\title{
THE USE OF RESEARCH-BASED INFORMATION SYSTEM DEVELOPMENT METHODS
}

\author{
Karin Hedström \\ Emma Eliason \\ ESA \\ Örebro University \\ SE-701 82 Örebro \\ Sweden
}

\begin{abstract}
This paper discusses how research-based knowledge in the form of an information systems development method (ISDM) is used in practice. The paper outlines a theoretical model for analyzng the uses of these methods as well as research results in general. The data are mainly based on research on a consultant's use of a specific ISDM. The use of ISDMs is discussed in the terms of a number of functions, and the usefulness of these functions is illustrated by empirical data.
\end{abstract}

\section{INTRODUCTION}

There is a need for more knowledge on how practitioners use, adapt, and benefit from information systems development methods (ISDMs). The construction of methods is an important issue in the information systems (IS) field, and a considerable amount of research within IS still focuses on the development of new methods that are meant to guide and support practitioners working with the development of organizations and information systems. Even if research within the IS field is closely related to practice, there is still a lack of understanding of how ISD methods are used in practice (e.g., Wynekoop and Russo 1995, 1997). We, as researchers, sometimes assume that IS development methods are considered useful and that they are used the way we had anticipated. The methods we develop are often based on the rationality of the method 
designers (Stolterman 1991) and not enough attention has been paid to what extent ISDMs are used, what parts of a method practitioners use, and how these parts are used.

The purpose of this paper is to shed some light on the way practitioners use and adapt ISDMs. The paper addresses the issue of how knowledge workers, in this case one consultant who works with organizational change and development, used an ISD method called Change Analysis (e.g., Goldkuhl 1992; Goldkuhl and Röstlinger 1993), which was developed by researchers. Hedström (2000) worked with and observed how two consultants working with organizational change and development used research results in their professional practices. ${ }^{1}$ As only one consultant, Anders, had an IS focus, the findings presented here are mainly based on his use of research-based results in the form of an ISD method, but sometimes we refer to the other consultant, Fredrik, as well. Fredrik worked mainly with organizational change and development from a management and learning perspective. This work was conducted in the realm of a research project.

\section{KNOWLEDGE USE}

Scientific and everyday knowledge are developed in different ways, using different means and are, to a certain extent, based on different values, and, in order to act, we sometimes need to use knowledge based on research and sometimes knowledge based on everyday experiences. Knowledge based on science and experiences from our everyday life integrate and cooperate, and together they constitute the knowledge base we use in our actions. New knowledge "creeps" (Weiss 1980) into our consciousness and is mixed with our previous knowledge base without us knowing. When we act, we seldom ask ourselves what type of knowledge we use - scientific or everyday knowledge based on experience-we are concentrating on acting. Knowledge is based on experience and develops through action, interaction, and reflection. Knowledge development is an action-oriented as well as a social process. Knowledge is personal and aims at action. Practical knowledge in the form of methods work, for example, as a guide to competent action. This indicates a view of knowledge as more than information or data. Knowledge is developed through an interpretative process when we relate the data or information to our personal knowledge base, and this process of internalization changes our conceptions and understanding. A method is a type of knowledge, presented in a systematic way and made explicit by the method designer, with the purpose of guiding the

'For more details, see Hedströ m 1999. 
actions of a future method user. Methods are usually expressed as normative knowledge - knowledge that can help practitioners perform better work. When a practitioner uses a method designed by a researcher in the IS field, he or she uses knowledge based on research, and is thus using research results.

\section{METHOD FOR DATA COLLECTION AND ANALYSIS}

The study of the use of knowledge is not easy. However, we believe that one fruitful way of doing this is to conduct a longitudinal, interpretative, and deep case study (see Hedström 2000). The use of knowledge as well as of methods is context dependent, and Larsen (1980) and Wynekoop and Russo (1995) support this approach. Larsen claims that knowledge use and development should be studied from a time-perspective and a process-perspective because the use of knowledge depends on the specific situation and the time of its use (Larsen 1980, p. 430).

Hedström (2000) worked with and observed the consultants over three years (from 1996 to 1999), and the data collection was a combination of passive and active observation, interviews, and document analysis as well as more informal conversations. The document analysis covered the consultants' project notes, reports, and analyses. The analysis was conducted following a qualitative approach with grounded theory (Strauss and Corbin 1998) as the guideline and source of inspiration. The analysis was inductive and all of the findings were grounded in the empirical data. The data were categorized and formed into a tentative theory without using an explicit theory or concepts as a basis for the analytical process.

\section{THE FUNCTIONS OF RESEARCH-BASED KNOWLEDGE}

Why do practitioners use research-based knowledge in the form of methods? Methods are normative knowledge with the purpose of guiding the user so he or she acts in a better and more competent way. One way of observing the usage of knowledge is to analyze it in terms of its functions. This has been done in the social sciences, where there have been several studies on how government officials use research results in decision and public policy making (e.g., Sunesson and Nilsson 1989; Weiss 1979, 1980).

In this section, we outline a theoretical framework for the use of ISDMs based on the findings of Hedström's $(1999,2000)$ study, which was sensitized 
and compared with findings from other studies (Jensen and Johansson 1999; Molander 1996; Sunesson and Nilsson 1989; Weiss 1979, 1980). ${ }^{2}$

There are, of course, more types of research-based knowledge than methods. Much research has as its main objective to enlighten or raise certain issues. Research might help us see or name things we previously did not notice. In this paper, we focus on functions of research-based knowledge in the form of methods-but these functions are similar to other uses of research-based knowledge. Each knowledge usage involves several functions, even though, at any given time, there might be one that is more prominent than the others. With ISDMs, the instrumental function is always prominent. Methods are developed so they can help the method user act in a better and more competent manner in order to solve certain problems. Knowledge use is always interactive (compare with Weiss [1979], who sees the interactive function as one special category), because knowledge constantly integrates with other sources of influence, and it is very hard to tell what comes specifically from one single source.

The functions of research-based knowledge, and thus also of methods developed by researchers, are:

- Enlightenment-research might change our perspective and how we view things.

- Orientation ${ }^{3}$-research and researchers are often able to put words to things that we already know but have problems expressing. Research helps us to see, to conceptualize, and to focus.

- Instrumental-research is used as a means to solve problems.

- Confirmation - as research is seen as something desirable with high status, and results from research can be used as a way to confirm something one already knows.

- Legitimization - research results can be used as an argument to legitimize and support decisions or actions ahead of others.

\subsection{Enlightenment}

Many of the influences that creep (Weiss 1980) into our consciousness make us change the way we view ourselves and the world in which we live. Weiss

${ }^{2}$ The study focused mainly on an ISDM called Change Analysis (e.g. Goldkuhl 1992; Goldkuhl and Röstlinger 1993) and all of the examples are related to the usage of this specific method.

${ }^{3}$ This function is influenced by Jensen and Johansson (1999) and by Molander (1996). 
(1979) claims that the enlightenment function is probably the most common function of research-based knowledge and we believe that there is always a possibility that the function of enlightenment will occur in the use of knowledge.

Even if research results in a form of method that might not have been designed primarily to enlighten, it is nevertheless evident that this sometimes occurs. Methods have an underlying perspective that not only influences on what to focus (see orientation), but also how to work, and an ISDM with a different perspective might very well change the method user's perspective. One example is Anders who, in his use of Change Analysis, started to work much more as a tutor than he had previously. He changed his view on how he, as a consultant, should work with organizations and with change work. Instead of taking on the role of an expert and conducting the analysis and change work himself, he now works more as a tutor and tries to motivate and encourage people to work with organizational development and change work themselves. This is partly because Change Analysis encourages and facilitates dialogue, cooperation, and knowledge sharing. He says, for instance: "We work more as tutors now, than experts....it is better if the people who work in the organization do the work themselves."

Another example of the enlightenment function is Anders' change from viewing the organizational analysis as only a means toward implementing a computer system. Now he can view an organizational analysis as an important result in its own right. "I used to see results as something that had been developed, tested and implemented. But now I have realized that results can also be other things, like the description of the organization that we did."

\subsection{Orientation}

Methods help us focus on certain things that the creator of the method believes are important in order to act. They also create certain intellectual images of reality so the method user can develop a better understanding of the world with the purpose of acting in a more competent manner. By clarifying phenomena and putting words to certain issues, methods foster a specific way of viewing the world and can thus help the method user to act and solve problems. Fredrik claimed, for instance, that "research gives us important pictures of reality. Research can also produce pictures of reality other than the ones you get when you are always in the middle of it." Change Analysis focuses, for instance, on such things as problems, strengths, activities, and goals, which help focus the reality. 


\subsection{Instrumental}

Often when we talk about the use of practical knowledge as methods, we indicate knowledge as a way of solving a specific problem by selecting the best means possible. Instrumental knowledge may consist of general laws, techniques, rules of thumb, and specific technical skills within a profession (Molander 1996, p. 168). The objectives of research are, with this view, to develop techniques, technologies, and methods that can be used to solve a practical problem. Anders uses methods developed by researchers as an instrument for solving problems related to his practice: "we use action diagrams [a documentation technique used in Change Analysis (e.g., Goldkuhl 1992)] much more now."

\subsection{Confirmation}

In Hedström's $(1999,2000)$ study, confirmation was not explicitly related to the usage of methods, but to the use of research results in general. Fredrik stated that

our previous knowledge was confirmed with this study....the pictures we had before, were now more articulated and explicitly developed....The importance of working with and using theoretical knowledge has been strengthened.

Nevertheless, his indicates that the function of confirmation could also be important in the practitioners' uses of ISDMs. The method user might feel more confident if he or she uses a method that has been developed by researchers.

\subsection{Legitimization}

One function of using research-based knowledge in the form of methods has been to legitimize the consultants' work for future and current employers. Anders feels that he can more easily argue for a comprehensive and thorough organizational analysis when researchers support this way of working. That research results are used to strengthen arguments and support decisions is confirmed by earlier studies (e.g., Sunesson and Nilsson 1988; Weiss 1979). Anders says: 
$\mathrm{He}$ [a high-level civil servant in the local government] has realized the value of having consultants with deep knowledge about the organizations. There has been a complete change of attitude, thanks to the project. They listen more to us now. Even if the things we now talk about are the same as before.

\section{SUMMARY AND CONCLUSION}

The discussion and analysis of the use of research-based ISDMs in the form of functions has proved fruitful as it helps us see how and in what situations practitioners use research results as, for instance, in ISDMs. The most common function of using research-based knowledge as ISD methods seems to be its enlightenment function. The use of knowledge changes the way we view things, our attitudes, and our perspectives. Another more obvious and perhaps conscious use of research-based knowledge concerns research's legitimizing function. We, as researchers, and the IT consultant we worked with were surprised that research can have such a high status. Anders experienced a complete change of attitude when he worked with researchers.

Future research is needed to further ascertain whether these functions are valid in practitioners' usages of ISDMs. More interpretative and longitudinal studies are necessary if we want to understand how practitioners use ISDMs, and we also need to study the use of ISDMs developed by other practitioners, such as consultants. Knowledge is context-dependent as well as time-dependent and cannot be studied in isolation. We need to study knowledge and knowledge use when it happens and where it happens.

\section{ACKNOWLEDGMENTS}

This research has been performed with financial support from Örebro University and the Swedish association of local authorities.

\section{REFERENCES}

Goldkuhl, G. "Contextual Activity Modeling of Information Systems," in Proceedings of the Third International Conference on Dynamic Modeling of Information Systems. Noordwijkerhout, Holland, June 9-10, 1992.

Goldkuhl, G., and Röstlinger, A. "Joint Elicitation of Problems: An Important Aspect of Change Analysis," in Human, Organizational, and Social Dimensions of Information Systems Development, D. Avison, J. E. Kendall, and J. I. DeGross (eds.), Amsterdam: Elsevier Science Publishers B.V., 1993, pp. 107-125. 
Hedström, K. "Researchers and Practitioners: A Study About Consultants' Use of Research-based Knowledge," in Proceedings of the Fifth Americas Conference on Information Systems, W. D. Haseman and D. L. Nazareth (eds.), Milwaukee, WI, August 13-15, 1999, pp. 851-853.

Hedström, K. Kunskapsanvändning och kunskapsutveckling hos verksamhetskonsulter erfarenheter frän ett FoU-samarbete. [Consultants' Use and Development of Knowledge Experiences from a Cooperation between Researchers and Practitioners]. Licentiate dissertation, IDA, Linköping University, 2000.

Jensen, C., and Johansson, S. "Research Utilization Among Symbol Producers: Diffusion or Translation?" presentation at Högskola och Samhälle i Samverkan (Universities and Society in Cooperation) Conference (HSS'99), Falun, Sweden, March 16-18,1999.

Larsen, J. "Knowledge Utilization: What Is It?" Knowledge: Creation, Diffusion, Utilization (1:3), 1980, pp. 421-442.

Molander, B. Kunskap i handling. [Knowledge in action], Gothenburg, Sweden: Daidalos, 1996.

Stolterman, E. "How System Designers Think About Design and Methods," Scandinavian Journal of Information Systems (3), 1991, pp. 137-150.

Strauss, A., and Corbin, J. Basics of Qualitative Research. Techniques and Procedures for Developing Grounded Theory ( $2^{\text {nd }}$ Edition), Thousand Oaks, CA: Sage Publications, 1998.

Sunesson, S., and Nilsson, K. "Explaining Research Utilization: Beyond 'Functions'," Knowledge: Creation, Diffusion, Utilization (10:2), 1988, pp. 140-155.

Weiss, C. "Knowledge Creep and Decision Accretion," Knowledge: Creation, Diffusion, Utilization (1:3), 1980, pp. 381-404.

Weiss, C. "The Many Meanings of Research Utilization," Public Administration Review, September/October 1979, pp. 426-431.

Wynekoop, J., and Russo, N. "Systems Development Methodologies: Unanswered Questions," Journal of Information Technology (10), 1995, pp. 65-73.

Wynekoop, J., and Russo, N. "Studying System Development Methodologies: An Examination of Research Methods," Information Systems Journal (7), 1997, pp. 47-65.

\section{About the Authors}

Karin Hedström is a member of the research group VITS, Linköping University and obtained her licentiate degree in 2000 at IDA, Linköping University. She has been employed at Örebro University since 1995, and is currently working on her doctoral thesis. She can be reached by e-mail at karin.hedstrom@esa.oru.se.

Emma Eliason has been employed at Örebro University since 1999 and has just commenced her doctoral studies. She can be reached by e-mail at emma.eliason@esa.oru.se. 